RESENHA

\title{
Gestão da Inovação: a economia da tecnologia no Brasil
}

Paulo Bastos Tigre

Rio de Janeiro: Elsevier, 282 páginas, 2006.

\section{Maria Teresa Franco Ribeiro}

Prof. Adjunto da Escola de Administração/Núcleo de Pós-Graduação - NPGA /UFBA

Resenhar uma obra significa um esforço analítico e reflexivo sobre o pensamento e a contribuição de um autor sobre determinado tema ou assunto. Como fazer isso dissociado da caminhada do próprio autor? Conhecer sua trajetória nos ajuda a compreender o tema tratado e o método de abordagem. Assim, acho muito importante apresentar, mesmo que de forma breve, o professor Paulo Bastos Tigre. Paulo Tigre é Professor Titular do Instituto de Economia da Universidade do Rio de Janeiro e coordenador do Grupo de Estudo sobre a Economia da Inovação. É Ph.D. em Política Científica e Tecnológica pela Universidade de Sussex (Inglaterra, 1982), Mestre em Engenharia da Produção pela COPPE/URFJ (1978) e Bacharel em Economia pela URFJ (1974). Foi Diretor Financeiro e de Planejamento da COBRA - Computadores e Sistemas (1986-1988). É pesquisador do CNPq e autor de vários livros entre eles Computador Brasileiro: Induistria, Tecnologia e Dependência (1984), que lhe conferiu o Prêmio Harambus Simeonides da Associação Nacional de PósGraduação em Economia. Como o próprio autor ressalta na Introdução (p.VII), o livro expressa "uma visão integrada, reunindo e sistematizando 30 anos de experiência em pesquisa, ensino, consultoria e gestão empresarial na área de inovação, pautada principalmente na realidade brasileira”. Assim, o olhar 
que Paulo Tigre direciona à Gestão da Inovação é de alguém que compreende a inovação como o resultado de um processo econômico, sociocultural e político. Nessa perspectiva sendo a inovação e a sua gestão de natureza transversal, o método de abordagem precisa incorporar o diálogo com outras áreas do conhecimento, caminhando em direção à interdisciplinaridade.

O livro inicia a abordagem da Gestão da Inovação e da Economia da Tecnologia a partir das principais contribuiçôes teóricas e dos contextos históricos que as respaldaram e avança complexificando em termos do debate teórico e das diversas experiências internacionais e nacionais que dão conteúdo e clareza à importância da inovação como um dos elementos-chave do desenvolvimento, sinalizando os desafios envolvidos na sua gestão, principalmente em países como o Brasil.

Paulo Tigre aponta a importância e a necessidade de uma nova postura intelectual, como a abertura para o diálogo com diferentes áreas do conhecimento, a integração dialética entre a teoria e o objeto empírico, e a percepção da importância da história na compreensão e construção do presente e do futuro. Ao abordar a inovação e a tecnologia de forma complexa, como um ato não isolado e neutro, Paulo Tigre resgata a dimensão da economia política da inovação, apontando os desafios envolvidos na construção do desenvolvimento econômico brasileiro, intensificados com o acirramento da competitividade e da expansão do novo paradigma técnico-econômico a partir das novas TICs.

A temática da economia da tecnologia e da gestão da inovação tecnológica, principalmente a partir da década de 1970, tem tido contribuições importantes, decorrentes do debate internacional sobre os fatores que condicionam o desenvolvimento econômico. Os resultados pífios do processo de globalização, que acirram as desigualdades, aumentaram a concentração do capital, do conhecimento e da riqueza mundial e foram os grandes pilares dessas pesquisas (Lastres \& Cassiolato, 2005).

Paulo Tigre investiga e discute as bases teóricas que vêm respaldando esse debate, resgata e organiza com muito rigor as principais contribuições internacionais e nacionais sobre o tema e realiza um esforço de ilustrar o debate com situaçóes concretas, o que torna a leitura agradável e profundamente elucidativa. $\mathrm{O}$ foco na realidade brasileira vem preencher uma lacuna teórica e empírica, uma vez que a literatura internacional não dá conta das especificidades e singularidades dos processos de desenvolvimento da periferia, como o Brasil. 
A compreensão dessas especificidades exige uma combinação dos avanços da literatura internacional com a análise e o esforço de compreensão da realidade local, muito bem construídos nesse livro.

Para desenvolver essa proposição o livro divide-se em três partes que são, na verdade, dimensões da dinâmica inovacional e da sua complexidade ao longo da história. A primeira parte, Teorias Econômicas da Tecnologia, apresenta e discute os conceitos das principais contribuiçóes teóricas à luz dos contextos histórico-institucionais em que as tecnologias foram produzidas e difundidas. Assim, constitui-se dos capítulos cujos títulos explicitam as principais correntes analisadas: 1 .Teorias econômicas clássicas da tecnologia; 2. A tecnologia nas visões marxista e neoclássica; 3 . A era fordista e a concorrência oligopolista; e 4. O pós-fordismo e as novas teorias da firma e da tecnologia.

Nessa parte, o autor investiga como as teorias econômicas da firma têm incorporado a mudança tecnológica desde a Primeira Revolução Industrial. O resgate da história de algumas tecnologias como a máquina a vapor, a eletricidade e o motor a combustão interna ilustra a complexidade do processo de invenção e inovação e a importância da dimensão política-institucional na consolidação dessas inovações e as transformações que acarretaram em toda a economia. Essas transformações, como ressalta o autor, não são fáceis e rapidamente incorporadas pelas teorias, "não existe um corpo teórico único e coerente, pois as teorias estão condicionadas por diferentes filiações e baseiam-se em contextos institucionais históricos e setoriais diversos" (p.IX).

Dos autores mais importantes investigados, ressalta-se a contribuição de Schumpeter como um dos economistas que mais compreendeu as análises de Marx sobre a dinâmica capitalista e o papel da tecnologia no processo de desenvolvimento. Desenvolvimento aqui entendido como um fenômeno qualitativamente novo e não um crescimento derivado do aumento da população e da riqueza (p.44). A partir da interpretação schumpeteriana da firma, não apenas como um espaço de produção, mas também de inovação, abre-se um espaço para novas interpretaçóes do comportamento da firma, como a firma organizada, na perspectiva dos behavoristas, a firma instituição, que incorpora a dimensão social e política do contexto de sua atuação, e as contribuições de Coase (1937) com a Teoria dos Custos de Transação, que traz novas questóes sobre a natureza da firma, considerando esta como um tipo de arranjo institucional específico, alternativo ao mercado. 
Mais recentemente, a partir dos impactos econômicos, sociais e políticos do chamado novo paradigma técnico-econômico, protagonizado pela difusão das Tecnologias da Informação e Comunicação (TICs), as idéias de Schumpeter são retomadas pela corrente de pensamento evolucionista ou neo-shumpeteriana, bem como os institucionalistas, que abordam a firma numa perspectiva sistêmica, ressaltando assim a importância da relação desta com o ambiente externo como condicionante de seu desempenho tecnológico e competitivo (p.53). Essas contribuições ressaltam a natureza dinâmica da tecnologia, a racionalidade limitada dos agentes econômicos, ou seja sua natureza cognitiva e procedural; a ação dos agente se materializa ao longo do processo, não podendo ser predeterminada, além de rejeitarem qualquer tipo de equilíbrio tão caro aos economistas neoclássicos.

Assim, no lugar da maximização, introduzem o princípio da pluralidade do ambiente de seleção tecnológica e a importância do ambiente coletivo de aprendizado. Ou seja, a história importa, estando a acumulação da firma dependente da base de conhecimentos adquiridos anteriormente que não desvia de sua trajetória bem-sucedida a não ser por mudanças na conjuntura econômica ou na natureza da tecnologia (pág.61). A partir dessa análise, o autor alerta para a importância de se considerar a natureza multidisciplinar das firmas e da mudança técnica, nos esforços de formulação de novos conceitos para analisar esses fenômenos.

$\mathrm{Na}$ segunda parte, Paulo Tigre discute os aspectos meso-econômicos ou as relações entre inovação e competitividade. Para tanto, realiza uma revisão conceitual da inovação, difusão e dos condicionantes desse processo: o setor de atividade em que a empresa atua, a localização regional e as limitações e oportunidades abertas para a inovação segundo o porte da empresa. Apresentam-se, então, os seguintes capítulos: 5. Inovação e difusão tecnológica; 6. Fontes de inovação na empresa; 7. Setor de atividades, tamanho da firma e localização geográfica; 8. Inovação e competitividade internacional. Há aqui uma revisão detalhada e rigorosa dos conceitos que, conjugada com os casos, permite uma leitura crítica da sua formulação teórica e aplicação. O conceito schumpeteriano de inovação, ao associar-se a tudo que diferencia e cria valor ao negócio, focase na perspectiva da competitividade, tornando-se útil no trato da gestão tecnológica e organizacional.

Se a tecnologia não é exógena como vislumbravam os neoclássicos, ela 
também não pode ser considerada totalmente endógena. Paulo Tigre explora, com exemplos bastante atuais, as diferentes fontes de tecnologia usadas pelas empresas para inovar e provocar os impactos necessários sobre a competitividade. O processo de difusão é analisado em quatro dimensões distintas: direção ou trajetória tecnológica, ritmo ou velocidade da difusão, fatores condicionantes e impactos sociais, econômicos e ambientais/institucionais. Na discussão sobre as diversas fontes internas e externas de inovação que as firmas exploram o autor interfere com análises bastante atuais sobre o desempenho tecnológica de algumas empresas em países diversos e, especialmenteno Brasil. Enquanto nos países desenvolvidos os esforços em P\&D são importantes, nos países em desenvolvimento o esforço tecnológico ainda se dá fundamentalmente por meio da aquisição de máquinas e equipamentos incorporados às plantas existentes ou sob a forma de turn-key. Embora essa seja uma forma de absorção tecnológica, um país não pode prescindir do esforço tecnológico próprio e de uma indústria local de bens de capital que complemente a oferta internacional e que seja compatível com as necessidades locais (p.103). A tendência do pensamento dominante à universalização dos mercados, implícita no processo de globalização, questiona o conceito de "tecnologia apropriada", adequada a determinado contexto. Mas como ressalta o autor, esse é ainda um conceito pertinente e necessário ao desenvolvimento industrial dos países periféricos. A dimensão local do processo de inovação é fundamental para a exploração do conhecimento tácito, que "permite a diferença de capacitação entre empresas e constitui uma vantagem competitiva única” (p.104).

A inserção da geografia da firma, já tão explorada por Marschall (1860) volta a ser percebida como um determinante do padrão de especialização e da intensificação tecnológica de uma indústria. A presença de infra-estrutura social e tecnológica adequada é uma condição fundamental para o sucesso de uma empresa inovadora. Dentro dessa perspectiva, o conceito de Sistemas de Inovação aponta para a importância da sinergia dos atores envolvidos no processo de inovação, que inclui não apenas as instituições voltadas para as atividades de $\mathrm{p} \& \mathrm{~d}$, mas também a rede de interaçóes entre usuários e fornecedores, relação de trabalho, sistema jurídico e políticas governamentais (p.137). Esses sistemas podem ser analisados em suas dimensões nacional, supranacional, setorial e tecnológica, como esferas complementares, com formas de articulação idiossincráticas segundo o tipo de produto. 
A partir de estudos sobre os fatores que explicam a competitividade internacional de algumas empresas e setores, o autor ressalta o papel da inovação como "um aspecto do mosaico das questões geopolíticas e econômicas que compõem o comércio internacional”. Nesse sentido, mostra a importância de se compreender como se articula o padrão de especialização de um país e sua demanda por tecnologia. A eficiência dinâmica da indústria depende da capacidade doméstica de gerar e administrar mudanças tecnológicas utilizadas na produção. Para alcançar esses níveis de capacitação, os mecanismos de mercado não são suficientes, são necessárias políticas públicas que desenvolvam capacitação, infra-estrutura tecnológica e medidas de apoio sustentado à inovação (p.145). Nesse aspecto, o autor é enfático ao apontar os desafios da competitividade da indústria brasileira, uma vez que hoje, em termos gerais, suas bases competitivas se apóiam fundamentalmente em vantagens comparativas naturais, como a biodiversidade, recursos hídricos para a irrigação e geração de energia renovável, mineral e florestal (p.159).

A terceira parte do livro é sobre a Gestão da Inovação propriamente dita, uma atividade de natureza fundamentalmente microeconômica. $\mathrm{O}$ argumento-chave dessa parte é que o sucesso da incorporação de uma nova tecnologia depende do matching entre oferta de conhecimentos e a capacidade de as empresas absorverem de forma eficiente novos equipamentos, sistemas e processos produtivos. Ou seja, o resultado competitivo é fruto de uma estratégia tecnológica que depende da conjugação de fatores como: capacidade técnica da empresa, da sua força financeira e do mercado em que atua. Estão compreendidos nesta parte os seguintes capítulos: 9. Inovação e estratégia competitiva; 10. Integração entre estratégia competitiva e capacitação tecnológica; 11. Inovações organizacionais; 12 . Redes de firmas e cadeias produtivas; 13 . Gestão da inovação na economia do conhecimento.

Paulo Tigre explora os avanços na economia do conhecimento e os desafios que esta apresenta para as organizações, na medida em que novas competências e padrões de competição estão em fase de mudança. Muitos conceitos e princípios pensados para a economia industrial não dão conta das especificidades e potencialidades desconhecidas das trocas intensivas em conhecimento. $\mathrm{O}$ conhecimento torna-se cada vez mais importante para se ter acesso à informação, devido a sua codificação lingüística, técnica ou científica para a manipulação e transmissão. O conjunto de habilidades exigidas constitui o que 
se chama de capital humano de difícil reprodução. A organização em rede assume um papel-chave na economia do conhecimento na medida em que ela aumenta as economias externas, por meio das economias de escala e de escopo, ampliação dos mercados, aceleração do processo de inovação e aceso a competências tecnológicas críticas (p.216).

As inovações com caráter sistêmico, como as redes, aumentam seu valor à medida que mais usuários as adotam, em um processo conhecido como feedback positivo. A flexibilidade organizacional e a capacidade cognitiva para absorver novos conhecimentos constituem elementos críticos para a difusão de novas tecnologias. Segundo Tigre, avaliar as vantagens e desvantagens de se vincular a uma rede implica identificar os núcleos virtuosos, formados por nós em que a agregação de valor é relativamente maior, e os núcleos competitivos em que a competição por preço é mais acirrada. Ter essa capacidade não é tarefa fácil e é essencial para a formulação de estratégias competitivas consistentes. Segundo o autor, como a economia do conhecimento depende de padrões que assegurem a compatibilidade de diferentes subsistemas, o entendimento das implicações das decisões técnicas quanto à liberdade futura (não aprisionamento a um padrão) constitui um elemento essencial da gestão da inovação (p.256).

O esforço em abordar os pontos-chave da obra ainda está aquém da riqueza de sua contribuição para a formação teórica e empírica sobre a economia da tecnologia e gestão da inovação em nível internacional e no Brasil especificamente. A sua leitura é importante e fundamental para a graduação, e o método abordado com exemplos permite a compreensão e aplicação de conceitos hoje imprescindíveis na formação acadêmica e profissional. Os alunos da pós-graduação, além de bases teóricas e análises recentes dos desafios da gestão da inovação no Brasil, terão no final de cada capítulo sinalização de espaços importantes de pesquisa e orientações bibliográficas complementares. Esse livro é também essencial para os gestores públicos e privados de todas as áreas de atuação, tendo em vista o caráter transversal e multidisciplinar da gestão da inovação. Boa leitura. 